\title{
The Chinese Phillips Curve - Inflation Dynamics in the Presence of Structural Change
}

\author{
Paul G. Egan \& Anthony J. Leddin ${ }^{1}$
}

\begin{abstract}
This paper models inflation dynamics in China from 1987-2014 using a Phillips curve framework. The Phillips curve is generally estimated under the assumption of linearity and parameter constancy. The existence of structural breaks in China's inflation dynamics make standard linear models inappropriate tools for analysis however. Our results find that the Chinese Phillips curve is characterised by a non-linear relationship. The inflation/output relationship takes the form of a concave curve. This suggests that changes in the level of output effect inflation in China more strongly in periods when output is operating below its potential but the relationship is weaker when output is operating at or above potential. Based on these findings, the People's Bank of China (PBC) could consider output cost and policy response on a case by case basis depending on the level of output in relation to potential.
\end{abstract}

Keywords: China, Phillips Curve, Inflation, Markov Switching, Structural Breaks, Monetary Policy. JEL Codes: C52, E31, E32

\footnotetext{
${ }^{1}$ Paul G. Egan, School of Economics \& Finance at the University of St. Andrews, UK. Anthony J. Leddin, the Kemmy Business School, University of Limerick, Ireland. The authors' wold like to thank Sheng Fang, Xingsheng Lu, Lingxiang Zhang, Bernadette Andreosso-O Callaghan and Brendan Walsh as well as the two anonymous referees for their comments and suggestions. The financial support of the Irish Research Council (IRC) is greatly appreciated.
} 


\section{Introduction}

Over the past thirty years, Chinese macroeconomic dynamics have been characterised mainly by high GDP growth accompanied with erratic swings in both its business cycle and price level fluctuations. Maxfield (1997) states that consumer price inflation is among the primary problems confronting transition economies. China has been no different in this regard. Bell \& Feng (2013) offer a variety of reasons for this including the readjustment of the price system, the Chinese government's high growth model as well as the rising household and business debt brought about by the transition from a planned economy. As a result of increased integration into the global economy and continuing liberalisation, prices in China have also become increasingly market determined. Therefore, understanding the dynamics of inflation, and its relationship with other macroeconomic indicators, has become an important question both in theory and in practice, especially for central banks in the conduct of monetary and economic policy (Funke 2006).

The initial discovery of the negative inflation-unemployment relationship by Phillips (1958) and popularized by Samuelson-Solow (1960), has long been an important tool for monetary policy. The dynamics of inflation have changed substantially in most advanced economies over the past decades however, leading to a renewal of interest in the Phillips curve in academic literature, particularly since the mid 1990's. During this renewal, special interest was paid to the shape of the curve itself. Empirical evidence of the definitive shape of the Phillips curve for the US and other industrialised economies is mixed. Akerlof $e l$ al. (1996) and Debelle \& Laxton (1996) suggested that a convex Phillips curve was appropriate, Gordon (1997) argued in favour of a linear curve while Stiglitz (1997) found evidence of a concave curve. More recently, a growing branch of empirical and theoretical literature in the area has found significant evidence of asymmetries and non-linearity in the Phillips curve relationship (see for example De Veirman (2009), Chortareas et al. (2012) and Xu et al. (2015) for details².) Early studies of Chinese inflation dynamics used a standard linear Phillips curve framework. Oppers (1997) adopted a Phillips curve model over four different time cycles and found that inflationary episodes in China have generally been associated with increases in aggregate demand. Ha et al. (2003) demonstrate that the conventional Phillips curve fails to account adequately for China's inflation dynamics, mainly due to the difficulty in estimating the potential output of Mainland China, a problem which can be attributed to significant structural changes within its economy. Scheibe \& Vines (2005) estimate a partially forward-looking Phillips curve as well as a traditional backward-looking Phillips curve and discover that the output gap and the exchange rate play important roles in explaining inflation in China. Gerlach \& Peng (2006) found that a simple application of the Phillips curve does not fit Chinese data well, citing the tremendous structural changes and policy shifts in China during the estimation period 1982-2006. Conway et al. (2010) found that inflation reacts to the level of excess demand in the economy. Changes in the nominal effective exchange rate are also found to drive inflation in the estimation period, with currency appreciation working to bring down inflation. The majority of findings and resulting policy recommendations in these studies come with the caveat that Chinese data is

\footnotetext{
${ }^{2}$ Studies carried out using Japanese, Euro Area and US data respectively.
} 
sensitive to the sample period and that structural breaks in the time series should be accounted for in any estimations. This suggests that such standard econometric models aren't suitable for explaining macroeconomic dynamics in China.

Due to the institutional reforms and increased industrialisation that came with them, the Chinese economy has experienced massive structural transformation over the last three decades. Taking account of the fact that the Chinese economy has experienced such change in both its institutional structure and economic policy, there is a general consensus that any study of macroeconomic relationships in China will suffer from structural breaks and nonlinearity ${ }^{3}$. This has led to the emergence of a small number of papers that adopt non-linear estimation techniques to examine Chinese inflation. Hwang \& Wu (2011) examine the nonlinear effect of inflation on economic growth and conclude that high inflation harms economic growth, whereas moderate inflation benefits growth. Zhang (2013) models Chinese inflation using a four-regime logistic smooth transition autoregressive model and finds that the effect of shocks to price levels is transient and asymmetrical. Finally, Zhang (2017) finds China's inflation-output type Phillips curve may be positively sloped, negatively sloped, or even vertical in the short term, depending on different business cycles. Our paper will add to the relatively scarce literature on Chinese inflation dynamics by estimating a breakpoint model and a non-linear Markov switching model. These models will attempt to capture any non-linearity, breaks or asymmetry associated with the structural changes in the Chinese economy during and after the reform period. The breakpoint model is useful as it can examine the changing relationship over time, before and after a particular point or event, for example a specific reform or policy. The Markov switching model on the other hand examines the changing relationship depending on the state characteristics, for example high/low levels of output or stable/volatile levels of inflation. This technique will allow us to examine the 'shape' of China's Phillips curve. We believe that examining China's Phillips curve in this way is the key contribution of our paper. As the shape of the Phillips curve determines the cost of disinflation, it has important implications for the PBC's monetary policy. Policy recommendations can therefore be offered based on our findings.

\section{Price Reform and Inflation in China}

\subsection{Price Reform}

In the pursuit of reform to the overall economic structure of the Chinese economy, policymakers have always attached a great deal of importance to price reform. As part of the "Decision of the Central Committee on Economic Reform" adopted in October 1984, the importance and position of price reform to China's economic restructuring was clearly described. This landmark decision pointed out that prices were the most important

\footnotetext{
${ }^{3}$ Gerlach \& Peng (2006), Dickinson \& Liu (2007), You \& Sarantis (2012) and Zheng et al. (2012) all discuss the effect of structural breaks and non-linearity's in Chinese macro variables.

4 In order to implement the strategic planning adopted at the National Congress of the Communist Party of China, the Plenary Session of the Central Committee of the Communist Party of China discussed some major issues concerning deepening the reform comprehensively, and made a number of key decisions based on the discussions.
} 
regulatory means and the reform of the price system was the key to the success or failure of the overall reform structure (Jin \& Qian 1996)). The main objective of these reforms was to decontrol the administratively determined prices gradually and allow prices to be determined by market forces (Chow 2004). However, the Chinese government, aware of the problems that immediate liberalisation to prices might cause ${ }^{5}$, decided to introduce a two tiered or "dual track" pricing system. Introduced in the early 1980's, this system involved the features of the planned economy running simultaneously with the establishment of a free market system. The Chinese government allowed some state owned enterprises, which had reached or surpassed the production quotas as set out by the planned system, to sell their excess output at market prices, with the quota production remaining at the state set prices. Qian (1999) refers to this dual track pricing system as "price liberalisation at the margin." Economic agents were therefore allowed to participate in the market place at free market prices as long as they had fulfilled their obligations under the planned system. This first step in the direction of price liberalisation meant that both market prices, and the market for goods and services itself, became important resource allocation institutions in the very early stages of the reform process. It also meant that enterprises involved in the system were incentivized to maximise their inputs outputs and profits, thus aiding economic growth (Yuan 1999).

Prior to the adoption of reforms, the prices of almost all commodities in China were decided by the government. According to The National Bureau of Statistics (NBS), in 1978 $97 \%$ of all commodities sold by retail were decided centrally. Less than twenty years later in 1994, it was evident there had been a huge change in price determination by which time $94 \%$ of all retail commodities were determined by market forces. Indeed, by the end of the 1990 's, nearly all prices had been liberalised and those that remained under state control were adjusted towards market levels. Price liberalisation became a key driver of China's economic reform throughout the 1980's and 1990's with important price deregulations in 1985, 1989 and 1994 (Mehrotra \& Sanchez-Fung 2010)6 .

It should be noted however there are a several goods in China whose prices are still heavily regulated. These range from tobacco, teaching materials, basic telecommunication services, medicine, natural gas, water, electricity and postal services. However, in the spirit of price reforms which began back in the late 1970's, the National Development and Reform Commission (NDRC) have stated that $80 \%$ of the commodities and services still under price regulation would be liberalised by the end of $2016^{7}$.

\footnotetext{
${ }^{5}$ Chow (2004) argues that these problems would have included a sudden increase in prices by market forces of essential consumer goods which would affect the welfare of consumers and the disruption of state enterprises who for years had been supplied with low cost inputs under the centrally planned system.

6 Oppers (1997) points out however that the late 1980's also saw great setbacks in the price reform process. For example, Chinese authorities, in response to macroeconomic imbalances, introduced a "rectification" programme which included a part reversal of earlier price reforms. Naughton (2007) argues that this is one of the many tensions which led to the Tiananmen Square incident of 1989 which further interrupted reform.

7 China Daily article, March 2015, accessed at http:// usa.chinadaily.com.cn/business/2015-

05/06/content_20638925.htm
} 


\subsection{Inflation in China}

Figure 1(a) depicts the annual growth rate of CPI inflation in China from 1987 to 2014 . From a simple graphical analysis, it is clear that there have been two pronounced peaks of Chinese inflation in 1988, 1994-95 and more modest increases in 2004, 2008 and 2011. There have also been periods of deflation in 1998 to 1999 and again in 2001 to 2002. These variations in the price level coincided with a relatively stable real growth rate which fluctuated around $9 \%$ for the period.

As mentioned in the previous section, with the onset of the reform period, prices in China were gradually liberalised and deregulated. One of these deregulations occurred in 1987 and led to a huge increase in the price level, with inflation reaching close to $25 \%$. The PBC responded by introducing contractionary monetary policy in an attempt to dampen this increase in prices. While this policy was successful in curbing inflation, it proved to be overly effective and led to low GDP growth in the proceeding period. Low growth and inflation continued into the early 1990's. The 1992 period saw further price liberalisation, loosening monetary policy and credit controls by the PBC. China's GDP growth rate increased rapidly, as did the inflation rate which peaked at almost $27 \%$ in 1994 . This was aggravated by the over depreciation of the RMB when the official exchange rate was combined with the free market swap rate 8 (McKinnon \& Schnabl 2009). This was followed by monetary policy tightening by the PBC towards the end of 1994. Inflation then decreased almost as fast as it had increased in 1995. The adoption of a fixed exchange rate peg with the dollar, following a period of large devaluations, also helped to reduce inflation volatility. China's inflation has, for the most part, remained surprisingly low for two decades since then and has even included two periods of deflation. The last twenty years can therefore be characterised as China's low inflation period, with an average inflation rate of less than $3 \%$. This has all been set against the backdrop of rapid economic and credit growth. Given that there has been a clear shift in the level of inflation during the reform process, this paper will attempt to examine the underlying dynamics of Chinese inflation during this period.

\section{Data and Methodology}

\subsection{Data}

The estimations in this paper were calculated using quarterly data from 1987 to 2014 . The dependent variable in our estimations is China's Consumer Price Index (CPI) inflation rate. This data was sourced from the National Bureau of Statistics (NBS) and is available from 1987. For the level of excess demand, the output gap is used. A HP filter is often applied to real GDP data to obtain the output gap. While this approach is easy to implement, it suffers

\footnotetext{
8 Before 1994, China was still under the "dual" exchange rate regime, under which $80 \%$ of the foreign exchange trading volume was at the market rate, and only $20 \%$ at the official rate. The 8.7 RMB per USD rate was basically the market rate at the end of 1993. On January 1, 1994, China unified the "dual" exchange rate regime into a single one.
} 
from the drawback that it provides no economic understanding of the sources of growth. Thus, it is arguably best seen as a complement to the more rigorous production function approach to calculating China's output gap (Gerlach \& Peng 2006). While calculating China's output gap using a production function approach is beyond the scope of this paper, it is available thorough Oxford Economics Global Economic Databank ${ }^{9}$. Finally, the supply shock to the level of prices will be the log change in the nominal effective exchange rate (NEER) is used. This quarterly data is available from the IMF International Financial Statistics (IFS). The renminbi (RMB) exchange rate has received a great deal of attention both in the economic literature and in the media. Koivu (2009) argues that the foundation of Chinese monetary policy has been a fixed exchange rate, while politicians and policy makers in the US claim that China intentionally suppresses the value of the RMB through massive market intervention to raise the competitiveness of its exports. Because the authority adopted a defacto fixed exchange rate regime before July 2005 and still exerts influence on the value of the nominal exchange, it is of interest to examine whether keeping the value of domestic currency stable has helped to maintain price stability (Jiang \& Kim 2013). Figure 1 (a), (b) and (c) plot the variables used in the estimations ${ }^{10}$.

\subsection{Methodology}

\subsubsection{The Phillips Curve}

Gordon (2011) describes three Phillips curve equations for empirical testing. Firstly, the traditional Phillips curve relates inflation to some cyclical indicator and lagged values of inflation. It implies that inflation is a backward-looking phenomenon, produced by adaptive expectations or by price-setting behavior based on a backward-looking rule of thumb (Roeger \& Herz 2012). The traditional model has also included a role for supply shocks with variables such as the relative price of energy or import prices as a proxy. This gives us;

$\pi_{t}=\mu+\alpha(L) \pi_{t-1}+\beta \bar{y}_{t}+\gamma z_{t}+\varepsilon_{t}$

This original version is often labelled the triangle Phillips curve (TPC) simply because it incorporates three variables, that is lagged inflation, a measure of excess demand and a supply shock. In the above equation $\pi_{t}$ is the rate of inflation, $\pi_{t-1}$ is the lagged inflation rate, $\bar{y}_{t}$ is the level of excess demand, $z_{t}$ is the supply shocks, $\varepsilon_{t}$ is the disturbance term and $(L)$ is the lag operator. The lags of inflation are often interpreted as a proxy for inflation expectations and more generally to capture the observed persistence in inflation. The lagged inflation allows the TPC to include a pure persistence effect due to fixed-duration wage and price contracts, and lags between changes in crude materials and final product prices. The level of excess demand is represented by the output gap, defined as real GDP minus potential GDP, so that a positive output gap represents excess demand. The theory suggests

\footnotetext{
${ }^{9}$ We are aware that results are sensitive to the method used for the measure of the output gap. Therefore, the output gap and potential GDP calculated by Oxford Economics Global Economic Databank was compared to a HP filter of China's real GDP calculated by the authors. Both series were very similar as were estimations used with the different measures of the output gap.

${ }_{10}$ Before beginning the estimations, Augmented Dickey Fuller (ADF) tests were applied to specify the order of integration of the variables. All variables were found to be $\mathrm{I}(0)$ at least at the $5 \%$ significance level. Results available by request.
} 
that if the economy is operating above its potential output level, inflation will tend to rise and vice versa. This variable, $z_{t}$, can include changes in the relative prices of food, energy, and imports as well as changes in the trend growth of productivity. Perhaps the most common supply shock used in the Phillips curve literature is the change in oil prices. This may not be a suitable shock in the Chinese case due to the regulatory structure of domestic oil prices ${ }^{11}$ which means changes in oil prices tend to have a very small pass through effect on Chinese prices. Therefore the log change in the nominal effective exchange rate (NEER) is modelled as the supply shock ${ }^{12}$. The nominal effective exchange rate is included in the Phillips curve model partly to capture inflation in imported goods and is appropriate given the huge amount of imports in the Chinese economy and will attempt to pick up changes in pass through inflation.

The second empirical model described by Gordon (2011) is the new Keynesian Phillips curve (NKPC) which has been used widely in monetary policy literature. Originally formulated by Roberts (1995), the NKPC has been used more recently as part of the new Keynesian Dynamic Stochastic General Equilibrium (DSGE) framework as in Clarida et al. (1999). Derived from micro foundations, with optimal price setting by forward looking monopolistically competitive firms, this "purely forward" Phillips curve states that inflation depends upon expected future inflation as opposed to expected current inflation. The NKPC takes the following form;

$\pi_{t}=\mu+\alpha E \pi_{t+1}+\beta \bar{y}_{t}+\varepsilon_{t}$

In this specification, $\bar{y}_{t}$ is again the level of excess demand, $E \pi_{t+1}$ is expected future inflation and $\varepsilon_{t}$ is the disturbance term. One drawback of with this model is that purely forward looking Phillips curves do not get much empirical support. Lagged inflation remains an important determinant of inflation and many studies have shown that a purely backward looking model is preferred by the data (Fuhrer 1997, Rudebusch \& Svensson 1998, Linde 2001 and Roberts 2005). Purely forward looking models such as the NKPC on the other hand have performed poorly in empirical tests as they fail to capture inflation persistence observed in the data. Fuhrer et al. (2009) argue that there is little evidence that a forward looking Phillips curve provides a better estimation than that of a standard looking one. Gordon (2011) also states that the triangle model outperforms the NKPC while Rudd \& Whelan (2005) argue against the validity of the forward looking expectations.

Finally, Clarida et al. (1999) attempted to distinguish between the two interpretations of the triangle Phillips curve and the new Keynesian Phillips curve by estimating a hybrid specification, known simply as the hybrid new Keynesian Phillips curve (HNKPC). Their estimations found that forward looking expectations were significantly larger than backward expectations and interpreted this result as implying that the New Keynesian curve with forward looking expectations provides a good approximation of the true inflation process. This is given as;

$\pi_{t}=\mu+\alpha_{f} E \pi_{t+1}+\alpha_{b} \pi_{t-1}+\beta \bar{y}_{t}+\varepsilon_{t}$

11 While gradual price liberalisation has promoted convergence between international and domestic energy prices (OECD 2013), the price of oil and petroleum products in China are still highly regulated by the government.

12 This is defined in foreign currency unit per renminbi (RMB) such that an increase in this variable corresponds to an appreciation of the RMB. We therefore expect a negative sign for this variable in our estimations. 
The terms $\alpha_{f}$ and $\alpha_{b}$ are the weights attached to expected future inflation (forward looking) and lagged inflation (backward looking), respectively. While the authors find that this so called Hybrid NKPC fits the data well, there have been arguments against the relevance of the forward term in this specification. In fact, in their conclusion, Rudd \& Whelan (2005) give a clear warning against the use of the new Keynesian Phillips curve, or hybrid variations that place a large weight on forward looking expectations for policy analysis.

It is important to carefully choose the correct Phillips curve specification which is most suitable to act as the "benchmark" model for Chinese inflation. This decision needs to be economically and econometrically justified. It has been noted that the backward looking price setting is more prominent in emerging economies such as China. There are many possible reasons for this including a lack of credibility in the central banks or the adjustment of regulated price contracts which would ultimately cause a higher level of persistence (Gertler \& Rogoff 2002). We have already discussed the issues relating to the deregulation of prices in Section 2.1. Higher inflation rates and inflation volatility in the late 1980's and early 1990's may have also affected the credibility of the PBC during the reform period. For these reasons alone, one would expect an important role for the backward looking component of China's Phillips curve. Gordon (2011) also points out that there is no explicit treatment of the supply shock in the NKPC, instead these are suppressed in the error term. Given China's huge amount of imports and its controversial exchange rate policy, the treatment of external supply shocks may be an important factor in modelling Chinese inflation. This point is reiterated by Kapur (2013) in a study of Indian inflation. The author states that emerging economies such as India and China have more complex inflation dynamics than advanced economies in view of recurrent supply shocks. Therefore, it would appear that the traditional TPC would be the best specification for the Chinese Phillips curve. We will test this empirically in Section 4.

\subsubsection{Modelling Macroeconomic Variables in the Presence of Reform and Change}

Macroeconomic models are vulnerable to structural change in at least two related ways. Firstly, parameters can shift, introducing errors into historically estimated relationships. Secondly, macroeconomic models are generally based on a limited set of causal relationships, which may have been relevant in a historical period but can become irrelevant over time (Basdevant \& Hargreaves 2003). There has been strong evidence of the issue of structural breaks in macroeconomic data during an economies transition process. Therefore, empirical analysis of transition economies must account for the possibility of structural changes; otherwise inferences made from estimations will be misleading. Non-linearity on the other hand provides a different interpretation of shocks to macroeconomic variables depending on the state of the economy (Koop \& Potter 1999). The asymmetric reaction of macroeconomic variables in this manner is also symptomatic of an economy which has undergone large-scale institutional and policy changes such as China, as governments and central banks react to the ever changing conditions of the macro economy. 
With respect to the presence to both structural breaks and non-linearity in macroeconomic time series, brought about by structural and institutional change, a useful and well used approach is to use models with changes in the mean. Among these "change" models that have been used extensively for this purpose are the Markov switching model developed by Hamilton $(1990,1994)$ and the multiple breakpoint model developed more recently by Bai \& Perron $(1998,2003)$. While both models are useful for modelling structural change, they have distinctions that allow us to examine different characteristics. First of all, the multiple breakpoint model can tell us how the dynamics of a particular variable is changing over time. For example, it can examine if the relationship between inflation and output in China has changed from the first era of reform (1978-1992) and the second era of reform (1992 onwards) ${ }^{13}$. However, macroeconomic relationships do not just change over time, but may also display distinct patterns under different states or regimes. The Markov switching (MS) model allows us to examine these patterns among China's inflation data. Using two different "structural change models" should provide us with a much better understanding than standard models of inflation with stable parameters. As China's inflation dynamics exhibit sudden changes brought about by economic reform, modelling price levels using constant coefficients would lead to incorrect specification and inevitably incorrect policy recommendations and responses.

\section{Estimations}

\subsection{Standard Linear}

Table 1 shows the estimations of the three Phillips curve specifications outlined in Section 3.2.1. At first glance, it would appear that the TPC provides a fairly robust model for Chinese inflation dynamics. All of the coefficients have the correct sign and are statistically significant. The sum of the autoregressive coefficients $\pi_{t-1}$ and $\pi_{t-2}$, is high at 0.89 , which indicates that inflation has been very persistent in China over the estimation period ${ }^{14}$. Excess demand, represented by the deviation of output from its natural level, is correctly signed and significant with a coefficient 0.14 . This would suggest that deviations in the output from its natural or potential level played a role in inflation dynamics in China over the estimation period. The supply shock, expressed as changes in the NEER, while small in magnitude, -0.06 , is correctly signed and highly significant. ${ }^{15}$ The forward looking NKPC also provides a good fit to the data with a significant value for both expected inflation and the output gap. There is however evidence of autocorrelation in the residuals. The hybrid specification does not fit the data well however and also fails to pass the diagnostic tests for heteroscedasticity and autocorrelation.

The results of the linear model therefore seem to suggest that the backward looking TPC with a supply shock maybe the best linear benchmark to model Chinese inflation. It is important to note however that all three Phillips curve specifications failed the test for

\footnotetext{
13 Reform was not in the form of a one off policy or a "big bang" change in institutional systems. China adopted economic reforms gradually. By so doing, it has phased in market forces into an administered economy but without a fundamental ownership transformation into a privately owned economy (Yueh 2010). The reforms of the Chinese economy are often characterised into two distinct periods or "eras" - 1978-1992 and 1992 onwards. 14 All significant lags of inflation were included in the estimation.

15 As the NEER is defined in foreign currency unit per renminbi (RMB), an increase in this variable corresponds to an appreciation of the RMB.
} 
parameter stability. This test was carried out by applying the Quandt/Andrews SupF statistic $^{16}$. The stability assumption is strongly rejected by this $\operatorname{SupF}$ test for the linear model which suggests that the Chinese Phillips curve is not generated by a stable relationship and that some kind of structural break is present. The structural break detected in the TPC and NKPC estimations relates to a breakpoint in the 1994-95 period. The most obvious explanation for this breakpoint is the adoption of the dollar peg in 1994. After this period, there was a marked decrease in both the rate and volatility of inflation. McKinnon (2007) argues that the fixed exchange rate anchored China's inflation suggesting that the adoption of this pegged regime helped to end China's "roller coaster ride" in domestic inflation characteristic of the 1980's and early 1990's. This was not the only major policy change in this period however. There were also major reforms in the area of fiscal and banking policy. A main component of this was the disconnect of monetary policy from government fiscal transfers. Prior to these reforms, credit was often extended in excess of pre-planned budgets at the local government level (Girardin \& Ping 1997). The PBC would then ultimately be forced to fill the gap and contribute to the money supply thus causing inflationary pressure. During these reforms, policy banks were also created removing these requirements which meant that the PBC could focus more attention on rebalancing the macro economy. Added to this, there were continued price deregulations and liberalisations in 1994 as mentioned in Section 2.1. These factors may also have changed the dynamics of Chinese inflation.

\subsection{Breakpoint Model}

The standard linear model assumes that parameters do not vary across observations. Despite this assumption, it is accepted that structural change (the changing of parameters at dates in the sample periods) play an empirically relevant role in applied time series analysis. This is particularly true of economies that have experience reform and institutional change such as China. Therefore, a linear regression model that is subject to structural change is estimated. There has been a large volume of work targeted at developing testing and estimating methodologies for regression models which allow for change. The seminal work of Chow (1960) and Quandt (1960) developed the testing procedure for structural changes in a time series at a single specified, hence known, break date. This work was closely followed by Andrews (1993), Andrews \& Ploberger (1994), Andrews et al. (1996) and Bai \& Perron (1998), (2003) who attempted to develop methods that allow for estimation and testing of structural change at unknown break dates. The Bai-Perron (BP) procedure is particularly useful in such a case as it allows the user to find the number of breaks implied by the data ${ }^{17}$, as well as estimating the timing of the breaks and the parameters of the processes between breaks. The methodology can be used to estimate multiple structural changes in a linear model estimated by least squares. Consider the below Phillips curve model with $m$ breaks;

$\pi_{t}=\mu_{1}+\alpha_{1} \pi_{t-1}+\beta_{1} \bar{y}_{t}+\gamma_{1} z_{t}+\varepsilon_{t}, \quad t=1, \ldots ., T_{1}$

\footnotetext{
${ }^{16}$ This is a test for parameter stability at each of the different points of a time series. Pioneered by Quandt (1960) and developed by Andrews (1993), it tests for one or more structural break points in the sample of a specific regression equation. It is prudent to test for structural breaks in this manner when the time series in question has experienced shocks and abrupt policy changes like those experienced by the Chinese economy.

17 In other words it tests for multiple breaks at unknown dates
} 
$\pi_{t}=\mu_{m}+\alpha_{m} \pi_{t-1}+\beta_{m} \bar{y}_{t}+\gamma_{m} z_{t}+\varepsilon_{t} \quad t=T_{m+1}, \ldots \ldots, T$

Where the breakpoints $\left(T_{1}, \ldots \ldots T_{m+1}\right)$ are treated as unknown. The Bai-Perron estimation is based upon least square estimates of $\mu_{i}, \alpha_{i}, \beta_{i} \& \gamma_{i}$ obtained by minimizing the sum of squared of residuals

$\sum_{i=1}^{m+1} \sum_{t=T_{i-1}+1}^{T_{i}}\left(\pi_{t}-\mu_{i}-\alpha_{i} \pi_{t-1}-\beta_{i} \bar{y}_{t}-\gamma_{i} z_{t}\right)^{2}$

To determine the number of breakpoints the "sequential process" suggested by Bai-Perron is used. The first step is to test the null hypothesis that there is $l=0$ structural breaks using the SupF test. If the null hypothesis of $l$ breaks is rejected in favour of the $l+1$ breaks alternativre, the test is applied to each sub-sample and so on, until rejection fails.

Table 2 illustrates the results of the breakpoint model. The results indicate that the Phillips curve relationship held across period's 1987Q3-1994Q1 (Period 1 hereafter) and 1994Q2-2014Q3 (Period 2 hereafter). The results suggest that inflation persistence was relatively high across both Period 1 and Period 2 and actually increased over time, with the sum of the autoregressive coefficients increasing from 0.58 to 0.79 . Inflation persistence is defined as the tendency for price shocks to push the inflation rate away from its steady state-including an inflation target-for a prolonged period. The increase in inflation persistence has important policy implications for the PBC. High inflation persistence renders the $\mathrm{PBC}$ monetary policy less effective as it will delay the response of inflation to various shocks. It will also prolong any inflation and output effects of monetary policy actions. What may be surprising is that the persistence increased at a time when further reforms were introduced in the banking sector which would have actually given the PBC greater power and autonomy. The reaction of excess demand (deviations of output from its natural level) is both correctly signed and significant across both periods. This relationship is stronger in Period 1 than in Period 2. To get a more detailed analysis of this relationship we can analyse the summary statistics in Appendix A. From these statistics we can calculate the effect of a $1 \%$ standard deviation (S.D.) in the independent variables to the inflation rate. In Period 1, a 1\% S.D. of the excess demand variable, the output gap, results in $0.23 \%$ change in the inflation rate. In Period 2 the effect is smaller, with the same change in the output gap leading to just a $0.07 \%$ change in inflation ${ }^{18}$. This suggests that the inflation/output relationship has weakened since 1994 and that there has been a flattening of the Philips curve relationship in China. The flattening of the Chinese Phillips curve can be seen graphically in Figure 2 which plots a simple inflation/output relationship across both periods. This flattening of the Phillips curve could have important policy implications. In one respect, it would make the PBC's task a little easier as they would not need to be overly concerned between temporary imbalances between demand and supply. However, it would also make responding to any inflation shocks more difficult as the PBC would need to adjust its monetary policy and reduce output considerably more to bring inflation back to the target level. In Period 1, the effect of the supply shock, which is represented by a change in

18 The standard deviations (S.D.) are calculated by multiplying the coefficient given for the independent variable by the S.D. of that variable divided by the standard deviation of the inflation. The calculation for example using the output gap in Period 1 is $0.68 *(2.4 \% / 7.2 \%)=0.23 \%$ 
the NEER, is incorrectly signed and not significant indicating that the exchange rate played no meaningful role in inflation prior to 1994. In Period 2, the NEER has both the correct negative sign and is also highly significant with a coefficient of -0.11 . This suggests that changes in the exchange rate had a significant effect on the inflation rate during the 19942014. The summary statistics in Appendix A indicate that this period, Period 2, can be characterised as a relatively low and stable period of Chinese inflation. The results indicate that the PBC's exchange rate policy may have been a factor in the low and stable inflation period. It is important to note that the increase in the significance of the NEER corresponds to a diminished effect of output on inflation. This also suggests that China's exchange rate regime in this period, Period 2, may have played a role in the breakdown of the inflation/output relationship.

\subsection{Markov Switching Model}

While the estimations in Section 4.2 provide a better insight into the inflation process in China than the standard linear model, the breakpoint model is limited in that it does not allow a switch between different states or regimes. Even a simple graphical analysis of Figure 1(a) would suggest that there may have been a switch in inflation dynamics with both periods of high inflation and periods of deflation occurring during the estimation. Therefore, we evaluate the Chinese inflation process through a Markov switching (MS) model. The MS model will not just identify different characteristics over time as in the breakpoint model, but will characterise relationships depending on the state of the economy and the stage of the business cycle. Many economic time series occasionally exhibit dramatic breaks in their behaviour, associated with events such as financial crises or abrupt changes in government policy (Hamilton 2005). The Chinese economy in particular has experienced tremendous structural changes in recent decades, associated with the gradual opening of the economy along with the changes in its institutions and policies. The breaks in the time series associated with these events make linear models inappropriate for analysing macroeconomic variables over time. To capture any non-linearity3, a model of Chinese inflation dynamics using the Markov switching (MS) model of Hamilton (1994) is estimated. The MS model is so called because the switching mechanism is controlled by an unobserved state variable $s_{t}$ that follows a first order Markov chain process. An interesting feature of the MS model is that the filtered probabilities can be interpreted as the agent's belief that the economy is in one of the possible states that describe the economy. It is also a very useful technique as the unobserved or latent state variable can be linked to an observable event, policy or characteristic.

By fitting the our Phillips curve equation to the MS framework, we get:

$\pi_{t}=\mu_{s t}+\alpha_{s t} \pi_{t-1}+\beta \bar{y}_{t_{s t}}+\gamma z_{s t}+\varepsilon_{t}$

Where $\varepsilon_{t} \sim$ i.i.d. $N\left(0, \sigma_{\varepsilon, s t}^{2}\right)$ and with unobserved state $s_{t}$, which is assumed to follow a Markov chain of order 1 with transition probabilities $p_{i j}$. The transition probability $p_{i j}$ gives the probability that state $i$ will be followed by state $j$.

$P_{i j}=\operatorname{Pr}\left[s_{t}=j \mid s_{t-1}=i\right], \quad \sum_{j-1}^{M} p_{i j}=1, \quad \forall i, j=1, \ldots . M$ 
This is often then written in an $(M \times M)$ matrix $P$, called a transition matrix:

$\mathrm{P}=\left[\begin{array}{cccc}p_{11} & p_{21} & \cdots & p_{M 1} \\ p_{12} & p_{22} & \cdots & p_{M 2} \\ \vdots & \vdots & \cdots & \vdots \\ p_{M M} & p_{2 M} & \cdots & p_{M M}\end{array}\right]$

The row $i$, column $j$ element of $P$ is the transition probability $p_{i j}$. To demonstrate, in the above matrix, the row 2 column 1 element gives the probability that State 1 will be followed by State $2^{19}$. The estimation of the model depends on maximum likelihood. The maximization of likelihood function of the model requires an iterative estimation technique to obtain estimates of the parameters of the model and the transition probabilities ${ }^{20}$. With the parameters identified, it is then possible to estimate the probability that the variable of interest, in this case Chinese inflation, is following a particular regime. It is also possible to derive the smoothed state probabilities which indicate the probability of being in a particular regime or state. Before estimating the Markov switching Phillips curve, the number of states or regimes to be included in the model must be chosen. As there are often relatively few transitions among states, it is difficult to estimate strictly exogenous explanatory variables accurately. For this reason, most applications assume only two or three states (Hamilton 2005). Tests for both a two-state and three-state Markov switching Phillips curve were carried out with the three-state model being rejected against the twostate model

Table 3 reports the estimation the MS Phillips curve, Figure 3 plots the states estimated by the model along with a plot of the inflation rate and Appendix A provides summary statistics for both states. From Figure 3 we can see that inflation switches back and forth frequently from State 1 to State 2. Overall, the state properties indicate that State 1 lasts slightly longer than State 2 in the estimation period. The typical duration of each state is twelve quarters for State 1 and nine quarters for State 221. The coefficients for the lag of inflation show that inflation persistence is high in both State 1 and State 2. The high inflation persistence across the entire sample is consistent with the paper's previous estimations which may point to the lack of credibility and transparency of the PBC. It is also important to note that inflation persistence is particularly high in State 2 which is often characterised by decreasing inflation. This suggests that Chinese markets are not confident in the PBC controlling inflation even when inflation is decreasing. The output gap is highly significant and correctly signed in State 1 but is not statistically significant in State 2. A 1\% S.D. in the output gap in State 1 will have a $0.11 \%$ S.D. effect on the inflation rate. The supply shock variable $z_{t}$, represented by changes in the NEER, is found to be significant and to have the correct negative sign across both states of the model. This implies that if the Chinese

\footnotetext{
${ }^{19}$ Let us for example, say that at time $t$, the state of the economy $s_{t}$ is classified as either high inflation in $s_{t}=1$ or low inflation in $s_{t}=2$. Let us also assume that the model gives us a probability of $95 \%$ of being $p_{11}$ and $5 \%$ of being $p_{21}$. What these values tell us is that if the economy is in a state of low inflation in the previous period, it tends to stay in a low inflation state with a very high probability of $95 \%$. On the other had the probability of being in a low inflation state in the previous period and switching to a high inflation state is low at just $5 \%$

${ }^{20}$ For more details on these technique and the maximum likelihood see Hamilton (1994) and Kim \& Nelson (1999).

21 This is calculated by $\frac{1}{1-P_{i i}}$
} 
exchange rate appreciates over time, it will have a negative influence on the Chinese inflation rate. The reaction of inflation to changes in the NEER increases as the economy moves from State 1 to State 2. A 1\% S.D. in the NEER in State 1 and 2 leads to a $0.01 \%$ and $0.18 \%$ S.D. in the inflation rate respectively.

\subsection{Summary of Results}

The estimations in Sections 4.2 and 4.3 provide an interesting perspective on China's inflation dynamics over the last three decades. The breakpoint model finds that from 19871994, the deviations of output from its natural level had a significant effect on the inflation rate. The exchange rate does not affect inflation during this period. From 1994-2014 however, the exchange rate does have a significant effect on the inflation rate and the effect of deviations of output from its natural level to the price level has decreased significantly. Inflation persistence remained high during both periods. The non-linear Markov switching estimation has findings similar to that of the breakpoint model. It found that China's inflation process can be characterised by two states. In State 1, the inflation rate is significantly responsive to the output gap while changes in the exchange rate are also significant but small in magnitude. In State 2 however, the effect of the exchange rate becomes stronger and deviations in the level of output from its natural level becomes insignificant. This suggests a possible trade-off between China's exchange rate policy and monetary policy responses.

What we find most interesting from the results of both our breakpoint and Markov switching estimations is that the Chinese Phillips curve would appear to be concave in shape $^{22}$. The idea of the concave Phillips curve was proposed by Stiglitz (1997), Eisner (1997) and further developed by Filardo (1998). A concave Phillips curve is an upward sloping curve that flattens as output rises above its natural or potential level. The curve is steeper at levels of output below potential. A concave Phillips curve points to the declining sensitivity of inflation to the strength of the economy. While a concave Phillips curve may seem like an unconventional idea, Stiglitz (1997) argues that it can often exist in an economy where firms are not purely or perfectly competitive. This would seem to fit the Chinese case when you consider such characteristics as the dominance of large state owned enterprises, state monopolies in sectors such as utilities, telecommunications, transport, asset monopoly ${ }^{23}$ as well as regulated markets for certain sectors, such as energy prices. As firms like this have pricing power and thus the ability and desire to influence their market share, they will be more reluctant to raise prices than to lower them. In this case, firms will respond to an increase in economic activity with more muted price changes and larger output changes than to a similar decrease in economic activity (Filardo 1998).

In the presence of a concave Phillips curve, the PBC would need to take significantly more action to reduce inflation when the level of real output is at or above its potential level. In other words, the output cost of reducing inflation would therefore be higher than if output was below its potential level. On the other hand, the risks of taking more aggressive

22 Figure 4 gives a representation of a concave Phillips curve (Filardo 1998).

23 The assets monopoly is a key feature of the Chinese system. Although in theory the SOEs are publicly owned, citizens are not the shareholders. Instead, appointed government agents hold a monopoly over these assets. This phenomenon leads to inefficiencies, a lack of innovation, inequitable distribution, corruption, and imbalances in the economic structure (Duan \& Saich 2014) 
policy measures in order to increase output above its potential might be lower than if the curve were both convex and linear. As the shape of a Phillips curve therefore determines the cost of disinflation, it has important implications for the PBC's monetary policy. It means that the effectiveness of China's monetary policy actions will depend on whether the economy is operating below potential, around potential or above potential output.

\section{Conclusion}

This paper models inflation dynamics in China from 1987-2014. The results of the standard linear model revealed that the Chinese Phillips curve is not generated by a stable linear relationship and that some kinds of structural break and non-linearity is present. This implies that a standard linear Phillips curve for China would provide misleading information with regard to inflation dynamics and would ultimately lead inappropriate policy response. A breakpoint model and Markov switching model were therefore estimated in an attempt to provide a better understanding of the inflation process in China. The results of the breakpoint model and the Markov switching model were similar and seem to provide a more robust analysis of the inflation process in China. The breakpoint model found a that after 1994 both the persistence of inflation and the effect of changes in the exchange rate increased, while the response of inflation to deviations in the level of output became insignificant. What was perhaps most interesting is that the estimations suggest that the Chinese inflation/output relationship in concave. A concave Phillips curve is an upward sloping curve that flattens as output rises above its natural or potential level. The curve is steeper at levels of output below potential. A concave Phillips curve points to the declining sensitivity of inflation to the strength of the economy. The results of the Markov switching model are concurrent with the estimations of the breakpoint model. First, the results reveal that inflation in China is characterised by two states - State 1 \& State 2. Consistent with the breakpoint model, the two-state MS model indicates that the Chinese Phillips curve appears to have a concave slope, reflecting the declining sensitivity of inflation to the strength of the economy. It suggests that inflation is more responsive to output when the economy is operating below the potential level.

The result of this paper provide a number of possible implications for Chinese policy makers. High levels of inflation persistence across all three models would appear to underline the need for clear and transparent signals on behalf of the PBC in order to adequately anchor inflation expectations. Uncertainty regarding the inflation objectives of a central bank will usually cause inflation to exhibit a high degree of persistence. A more credible inflation target policy which is focused more on price rather than exchange rate stability would potentially reduce this persistence. Indeed, the Chinese exchange rate has long been a contentious issue for Chinese policy makers. The results of the estimations indicate that as changes in the exchange rate became more significant to the level of inflation, the deviation of output from its potential became less significant. This perhaps points to a recommendation of further flexibility of the RMB to allow greater scope for monetary policy response to inflation. Finally, there are important policy options relating to the concave nature of the inflation/output relationship. The estimations suggest that the cost of fighting inflation varies systematically depending on the strength of the economy. This would indicate that the lesson for the PBC in terms of monetary policy would be to 
consider output cost and policy response on a case by case basis depending on the level of output in relation to potential. The PBC would therefore benefit from policies that are more proactive in nature than suggested by traditional linear models.

\section{References}

AKERLOF, G. A., DICKENS, W. R. \& PERRY, G. L. 1996. The Macroeconomics of Low Inflation.

ANDREWS, D. W. K. \& PLOBERGER, W. 1994. Optimal Tests when a Nuisance Parameter is Present Only Under the Alternative. Econometrica, 62, 1383-1414.

ANDREWS, D. W. K. 1993. Exactly Median-Unbiased Estimation of First Order Autoregressive/Unit Root Models. Econometrica, 61, 139-165.

ANDREWS, D. W. K., LEE, I. \& PLOBERGER, W. 1996. Optimal change point tests for normal linear regression. Journal of Econometrics, 70, 9-38.

BAI, J. \& PERRON, P. 1998. Estimating and Testing Linear Models with Multiple Structural Changes. Econometrica, 66, 47-78.

BAI, J. \& PERRON, P. 2003. Computation and analysis of multiple structural change models. Journal of Applied Econometrics, 18, 1-22.

BASDEVANT, O. \& HARGREAVES, D. 2003. Modelling structural change: the case of New Zealand. Reserve Bank of New Zealand Discussion Paper Series, DP2003/03

BELL, S. \& FENG, H. 2013. The Rise of the People's Bank of China: The Politics of Institutional Change, Harvard University Press.

CHORTAREAS, G.,MAGONIS, G., \& PANAGIOTIDIS, T. 2012. The asymmetry of the New Keynesian Phillips Curve in the euro-area. Economics Letters, 114(2), 161-163.

CHOW, G. C. 1960. Tests of Equality Between Sets of Coefficients in Two Linear Regressions. Econometrica, 28, 591-605.

CHOW, G. C. 2004. Economic Reform and Growth in China. Annals of Economics and Finance, 5, 127-152.

CLARIDA, R., GALÍ, J. \& GERTLER, M. 1999. The Science of Monetary Policy: A New Keynesian Perspective. Journal of Economic Literature, 37, 1661-1707

CONWAY, P., R. HERD \& CHALAUX, T. 2010 Reforming China's Monetary Policy Framework to Meet Domestic Objectives, OECD Publishing.

DE VEIRMAN, D. 2009, What Makes the Output-Inflation Trade-Off Change? The Absence of Accelerating Deflation in Japan. Journal of Money, Credit and Banking, 41(6), 1118-1139.

DEBELLE, G. \& LAXTON, D. 1996. Is the Phillips Curve Really a Curve? Some Evidence for Canada, the United Kingdom, and the United States . IMF Working Paper, 199, 1-38

DICKINSON, D. \& LIU, J. 2007. The real effects of monetary policy in China: An empirical analysis. China Economic Review, 18, 87-111.

DUAN, P. \& SAICH, A. 2014. Reforming China's Monopolies. HKS Faculty Research Working Paper Series RWP14-023, May 2014.

EISNER, R. 1997. A new view of the NAIRU. In P. Davidson and J. Kregel (eds) Improving the Global Economy: Keynesianism and the Growth in Output and Employment. Cheltenham, UK and Brookfield

FIDRMUC, J. \& TICHIT, A. 2009. Mind the Break! Accounting for Changing Patterns of Growth during Transition. CEDI Discussion Paper Series, 09-02.

FILARDO,A.J. 1998. New evidence on the output cost of fighting inflation. Economic Review, Federal Reserve Bank of Kansas City, Issue Q3. 
FUHRER, J. 1997. The (Un)Importance of Forward-Looking Behaviour in Price Specifications. Journal of Money, Credit and Banking, 29, 338-350.

FUHRER, J., KODRZYCKI, Y.K., LITTLE, J.S. \& OLIVEI, G.P. 2009. Understanding Inflation and the Implications for Monetary Policy: A Phillips Curve Retrospective, MIT Press, Massachusetts

FUNKE, M. 2006. Inflation in Mainland China - Modelling a Roller Coaster Ride. Pacific Economic Review, 11, 413-429

GERLACH, S. \& PENG, W. 2006. Output gaps and inflation in Mainland China. China Economic Review, 17, 210-225.

GERTLER, M. \& ROGOFF, K. 2002. NBER Macroeconomics Annual 2002, Volume 17, pages 1-4 National Bureau of Economic Research, Inc.

GIRARDIN, E. \& PING, X. 1997. Urban Credit Co-Operatives in China, OECD Development Centre Working Papers 125, OECD Publishing.

GORDON, R. J. 1997. The Time-Varying NAIRU and its Implications for Economic Policy. The Journal of Economic Perspectives, 11, 11-32.

GORDON, R.J. 2011. The History of the Phillips Curve - Consensus and Bifurcation. Economica,78,10-50.

HA, J., FAN, K. \& SHU, C. 2003. The Causes of Inflation \& Deflation in Mainland China. Hong Kong Monetary Authority Quarterly Bulletin, September 23-31.

HAMILTON, J. D. 1990. Analysis of time series subject to changes in regime. Journal of Econometrics, 45, 39-70.

HAMILTON, J. D. 2005. Regime Switching Models. Palgrave Dictionary of Economics, (available at http://dss.ucsd.edu/ jhamilto/palgrav1.pdf)

HAMILTON, J.D. 1994. Time Series Analysis. Princeton University Press.

HWANG, T. \& WU, J. 2011. Inflation and Economic Growth in China: An Empirical Analysis, China and World Economy,19( 5), 67-84.

JIANG, J. \& KIM, D. 2013. Exchange rate pass-through to inflation in China. Economic Modelling, 33, 900-912.

JIN, H. \& QIAN, Y. 1996. Public versus private ownership of firms: evidence from rural China. The Quarterly Journal of Economics, 113, 773-808.

KAPUR, M. 2013. Revisiting the Phillips curve for India and inflation forecasting. Journal of Asian Economics, 25, 17-27.

KIM, C.H. \& NELSON, C.R. 1999. State Space Models with Regime Switching. MIT Press.

KOIVU, T. 2009. Has the Chinese economy become more sensitive to interest rates? Studying credit demand in China. China Economic Review, 20, 455-470.

KOOP, G. A. P \& POTTER, S. N. 1999. Bayes Factors and Nonlinearity: Evidence from Economic Time Series. Journal of Econometrics, 88, 251-281.

LINDÉ, J. 2001. The Empirical Relevance of Simple Forward- and Backward-looking Models: A View from a Dynamic General Equilibrium Model. Sveriges Riksbank (Central Bank of Sweden) Working Paper Series, 130.

MAXFIELD, S. 1997. Gatekeepers of Growth: The International Political Economy of Central Banking in Developing Countries, Princeton, NJ, Princeton University Press.

MCKINNON, R. \& SNHNABL, G. 2009. China's financial conundrum and global imbalances. BIS Working Papers, 227.

MCKINNON, R. 2007. Why China Should Keep Its Dollar Peg*. International Finance, 10, 4370.

MEHROTRA, A.N \& SÁNCHEZ-FUNG, J. R. 2010. China's monetary policy and the 
exchange rate. BOFIT Discussion Papers 10, Bank of Finland BOFIT Institute for Economies in Transition.

NAUGHTON, B. 2007. The Chinese Economy, Cambridge, Massachusetts, MIT Press.

OECD 2013. The People's Republic of China - Avoiding the Middle Income Trap: Policies for Sustained \& Inclusive Growth, September 2013, accessed at http://www.oecd.org/china/China-Brochure-eng-September2013.pdf

OPPERS, S.E. 1997. Macroeconomic Cycles in China. IMF Working Paper, 97/135.

PHILLIPS, A. W. 1958. The Relation between Unemployment and the Rate of Change of Money Wage Rates in the United Kingdom, 1861-1957. Economica, 25, 283-299.

QIAN, Y. 1999. The Process of China's Market Transition (1978-98): The Evolutionary, Historical, and Comparative Perspective. Journal of Institutional and Theoretical Economics, 1999, 151-171.

QUANDT, R. 1960. Tests of the Hypothesis that a Linear Regression System Obeys Two Separate Regimes, Journal of the American Statistical Association, 55, 324-330.

ROBERTS, J.M. 1995. New Keynesian Economics and the Phillips Curve. Journal of Money, Credit, and Banking 27, 975-984.

ROBERTS, J. M. 2005. How Well Does the New Keynesian Sticky-Price Model Fit the Data? Contributions to Macroeconomics, 5.

ROEGER, W. \& HERZ, B. 2012. Traditional versus New Keynesian Phillips Curves: Evidence from Output Effects, International Journal of Central Banking, 8(1), 87-109.

RUDD, J. \& WHELAN, K. 2005. New Tests of the New-Keynesian Phillips Curve. Journal of Monetary Economics, 52, 1167-1181.

RUDEBUSCH, G.D. \& SVENSSON, L.E.O. 1998. Policy Rules for Inflation Targeting. CEPR Discussion Papers

SAMUELSON, P. A. \& SOLOW, R. M. 1960. Analytical Aspects of Anti-Inflation Policy. The American Economic Review, 50, 177-194.

SCHEIBE, J. \& VINES, D. 2005. A Phillips Curve for China. Centre for Applied Macroeconomic Analysis, The Australian National University, Working Paper, 2/2005

STIGLITZ, J. 1997. Reflections on the Natural Rate Hypothesis. The Journal of Economic Perspectives, 11, 3-10.

XU, Q., NIU, X., JIANG, C. \& HUANG. 2015. The Phillips curve in the US: A nonlinear quantile regression approach, Economic Modelling, 49, 186-197

YUEH, L. 2010. A Stronger China. IMF Finance \& Development, 47, 8-11, accessed at http://www.imf.org/external/pubs/ft/fandd/2010/06/yueh.htm

YOU, K. \& SARANTIS, N. 2012. Structural breaks and the equilibrium real effective exchange rate of China: A NATREX approach. China Economic Review, 23, 11461163.

YUAN, Q. 1999. The Institution Foundations China's Market Transition. Paper prepared for the Annual World Bank Conference $n$ Development Economics, Washington DC.

ZHANG, L. 2013. Modelling China's inflation dynamics: An MRSTAR approach. Economic Modelling, 31, 440-446.

ZHANG, L. 2017. Modelling The Phillips Curve In China: A Nonlinear Perspective, Macroeconomic Dynamics, 21(02), 439-461.

ZHENG, T., WANG, X. \& GUO, H. 2012. Estimating forward-looking rules for China's Monetary Policy: A regime-switching perspective. China Economic Review, 23, 4759. 


\section{Appendix A - Summary Statistics}

SuMMARY STATISTICS FOR BREAK POINT MODEL AND MARKOV SWITCHING MODEL

\begin{tabular}{|c|c|c|c|c|}
\hline & \multicolumn{2}{|c|}{ Break Point Model } & \multicolumn{2}{|c|}{ Markov Switching Model } \\
\hline & Period 1 & Period 2 & State 1 & State 2 \\
\hline \multicolumn{5}{|l|}{ Inflation, $\pi_{t}$} \\
\hline Mean of $\pi_{t}$ & $10.43 \%$ & $3.62 \%$ & $4.55 \%$ & $6.03 \%$ \\
\hline Standard deviation of $\boldsymbol{\pi}_{\boldsymbol{t}}$ & $7.22 \%$ & $5.33 \%$ & $6.37 \%$ & $6.57 \%$ \\
\hline \multicolumn{5}{|l|}{ Output Gap, $\bar{y}_{t}$} \\
\hline Mean of $\overline{\boldsymbol{y}}_{\boldsymbol{t}}$ & $-2.71 \%$ & $0.01 \%$ & $-2.09 \%$ & $0.02 \%$ \\
\hline Standard deviation of $\overline{\boldsymbol{y}}_{\boldsymbol{t}}$ & $2.36 \%$ & $1.70 \%$ & $1.78 \%$ & $1.80 \%$ \\
\hline \multicolumn{5}{|c|}{ Nominal Effective Exchange Rate (NEER), $z_{t}$} \\
\hline Mean of $z_{t}$ & $-6.12 \%$ & $0.23 \%$ & $-0.25 \%$ & $-2.49 \%$ \\
\hline Standard deviation of $\boldsymbol{z}_{\boldsymbol{t}}$ & $12.58 \%$ & $9.65 \%$ & $5.22 \%$ & $14.88 \%$ \\
\hline
\end{tabular}




\section{TABLE 1 - PHILLIPS CURVE ESTIMATION - LINEAR MODEL(1988Q1-2014Q3)}

\begin{tabular}{|c|c|c|c|}
\hline Variable & $\begin{array}{c}\text { Triangle } \\
(1)\end{array}$ & $\begin{array}{c}\text { New } \\
\text { Keynesian } \\
(2)\end{array}$ & $\begin{array}{c}\text { Hybrid New } \\
\text { Keynesian } \\
\text { (3) }\end{array}$ \\
\hline \multicolumn{4}{|c|}{ Dependent Variable: China's CPI Inflation Rate } \\
\hline$\mu$ & $\begin{array}{l}0.01^{* * *} \\
(0.00)\end{array}$ & $\begin{array}{l}0.01^{* * *} \\
(0.00)\end{array}$ & $\begin{array}{l}-0.01 \\
(0.01)\end{array}$ \\
\hline$\pi_{t-1}$ & $\begin{array}{l}1.49^{* * *} \\
(0.07)\end{array}$ & - & $\begin{array}{l}0.51^{* * *} \\
(0.02)\end{array}$ \\
\hline$\pi_{t-2}$ & $\begin{array}{l}-0.60^{* * *} \\
(0.07)\end{array}$ & - & - \\
\hline$E_{t} \pi_{t+1}$ & - & $\begin{array}{l}0.92^{* * *} \\
(0.03)\end{array}$ & $\begin{array}{l}0.52^{* * *} \\
(0.02)\end{array}$ \\
\hline $\bar{y}_{t}$ & $\begin{array}{l}0.14^{* *} \\
(0.07)\end{array}$ & $\begin{array}{l}0.29 * * * \\
(0.09)\end{array}$ & $\begin{array}{c}0.01 \\
(0.04)\end{array}$ \\
\hline$z_{t}$ & $\begin{array}{l}-0.06^{* * *} \\
(0.01)\end{array}$ & - & - \\
\hline $\mathrm{R}^{2}$ & 0.96 & 0.92 & 0.98 \\
\hline LM F-Stat & 1.54 & - & $3.01^{* *}$ \\
\hline DW Stat & - & 0.74 & - \\
\hline SupF Stat & $\begin{array}{c}47.02^{* * *} \\
(1994 Q 2)\end{array}$ & $\begin{array}{c}20.12^{* * *} \\
(1995 Q 4)\end{array}$ & $\begin{array}{c}20.94^{* * *} \\
(1991 Q 4)\end{array}$ \\
\hline
\end{tabular}

\footnotetext{
${ }^{* * *},{ }^{* *}$ and ${ }^{*}$ denotes significance at the 1,5 and $10 \%$ respectively. HAC standard errors for the TPC are in parenthesis.
} 


\section{TABLE 2 - PHILLIPS CURVE WITH BREAKPOINT(S) (1987Q3-2014Q3)}

\begin{tabular}{ccc}
\hline \hline Variable & $\begin{array}{c}\text { Period 1 } \\
(1987 Q 3-1994 Q 1)\end{array}$ & $\begin{array}{c}\text { Period 2 } \\
(1994 Q 2-2014\end{array}$ \\
& & \\
\hline$\mu$ & $0.06^{* * *}$ & $0.01^{* * *}$ \\
& $(0.02)$ & $(0.01)$ \\
& $1.37^{* * *}$ & $0.98^{* * *}$ \\
$\pi_{t-1}$ & $(0.04)$ & $(0.15)$ \\
& $-0.79^{* * *}$ & $-0.19^{* * *}$ \\
& $(0.10)$ & $(0.13)$ \\
$\pi_{t-2}$ & $0.68^{* * *}$ & $0.23^{* *}$ \\
& $(0.17)$ & $(0.09)$ \\
$\bar{y}_{t}$ & 0.05 & $-0.11^{* * *}$ \\
& $(0.04)$ & $(0.02)$
\end{tabular}

$* * * * *$ and $*$ denotes significance at the 1,5 and $10 \%$ respectively. HAC standard errors are in parenthesis 
TABLE 3 - PHILLIPS CURVE WITH MARKOV SWITCHING MODEL (1988Q1-2014Q3)

\begin{tabular}{|c|c|c|}
\hline Variable & State 1 & State 2 \\
\hline \multicolumn{3}{|c|}{ Dependent Variable: China's CPI Inflation Rate. } \\
\hline$\mu$ & $\begin{array}{l}0.01^{* * *} \\
(0.01)\end{array}$ & $\begin{array}{l}0.03^{\star * *} \\
(0.01)\end{array}$ \\
\hline$\pi_{t-1}$ & $\begin{array}{l}1.02^{* * *} \\
(0.12)\end{array}$ & $\begin{array}{l}1.65^{\star * *} \\
(0.06)\end{array}$ \\
\hline$\pi_{t-2}$ & $\begin{array}{l}-0.29 * * * \\
(0.11)\end{array}$ & $\begin{array}{l}-0.69 * * * \\
(0.05)\end{array}$ \\
\hline $\bar{y}_{t}$ & $\begin{array}{l}0.38^{* * *} \\
(0.14)\end{array}$ & $\begin{array}{c}0.05 \\
(0.07)\end{array}$ \\
\hline$z_{t}$ & $\begin{array}{l}-0.02^{* * *} \\
(0.01)\end{array}$ & $\begin{array}{l}-0.08^{* *} \\
(0.01)\end{array}$ \\
\hline$p_{11}$ & 0.91 & - \\
\hline$p_{12}$ & 0.08 & - \\
\hline$p_{21}$ & - & 0.11 \\
\hline$p_{22}$ & - & 0.88 \\
\hline Duration of State & 11.9 quarters & 8.8 quarters \\
\hline
\end{tabular}

Notes: ${ }^{* * *}, * *$ and * denotes significance at the 1,5 and 10\% respectively. Standard errors are in parenthesis 
FIgURE 1 - INFLATION, OUtPUT GAP \& CHANGE IN THE NEER, 1987Q1-2014Q3

Source: Oxford Economics, National Bureau of Statistics (NBS) China \& author's calculations

(a) Inflation Rate

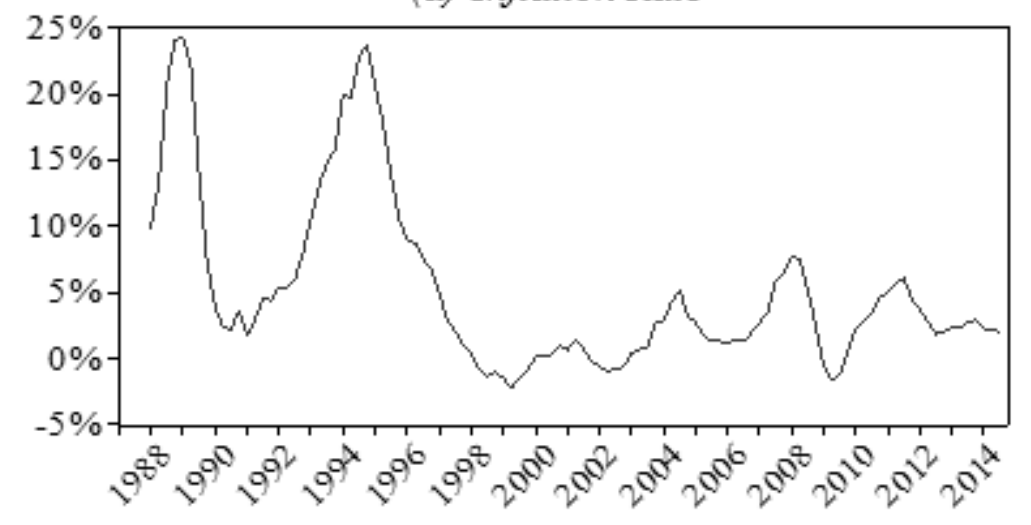

(b) Output Gap

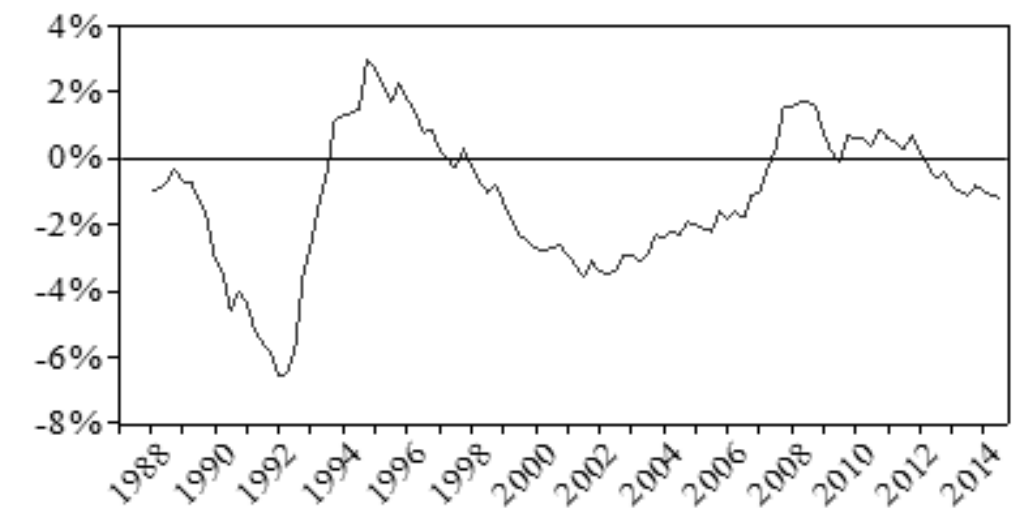

(c) Change in Nominal Effective Exchange Rate (NEER)

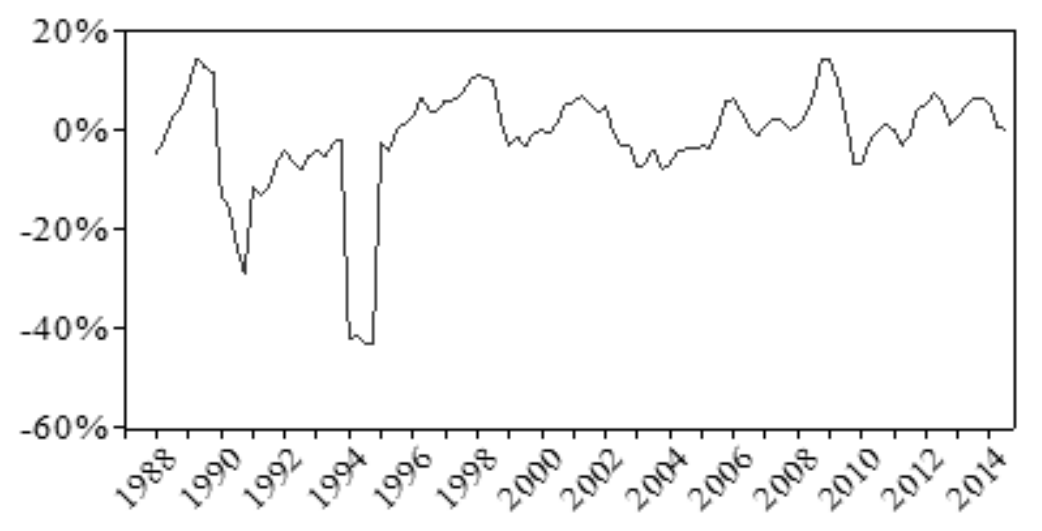


Figure 2 - Inflation/Output Gap Relationship Period 1 \& Period 2

Source: Author's calculations using simple linear estimation

(a) Period 1 1987Q3-1994Q1

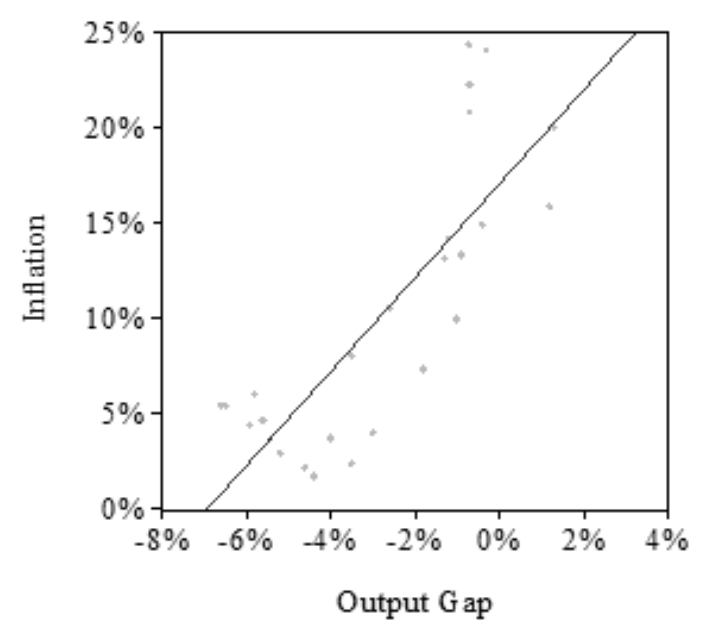

(b) Period $21994 Q 2-2014 Q 3$

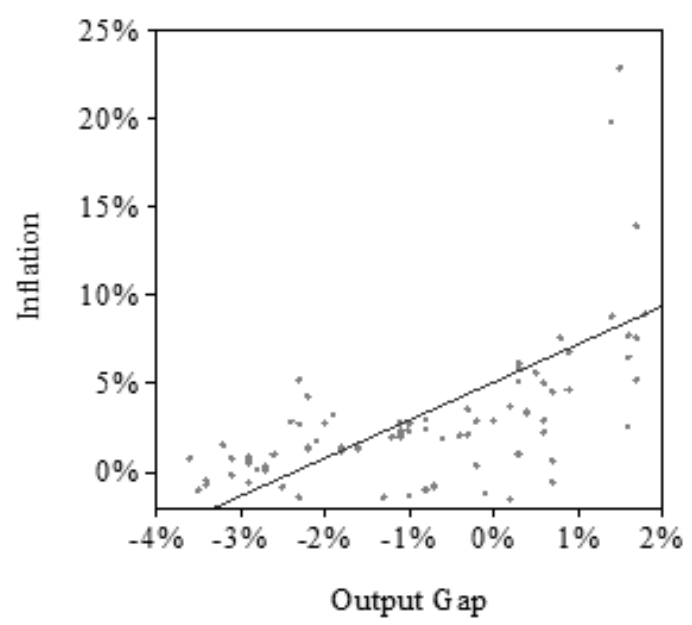


FiguRE 3 - INFLATION IN STATE 1 \& STATE 2

Source: Chinese NBS \& author's calculations

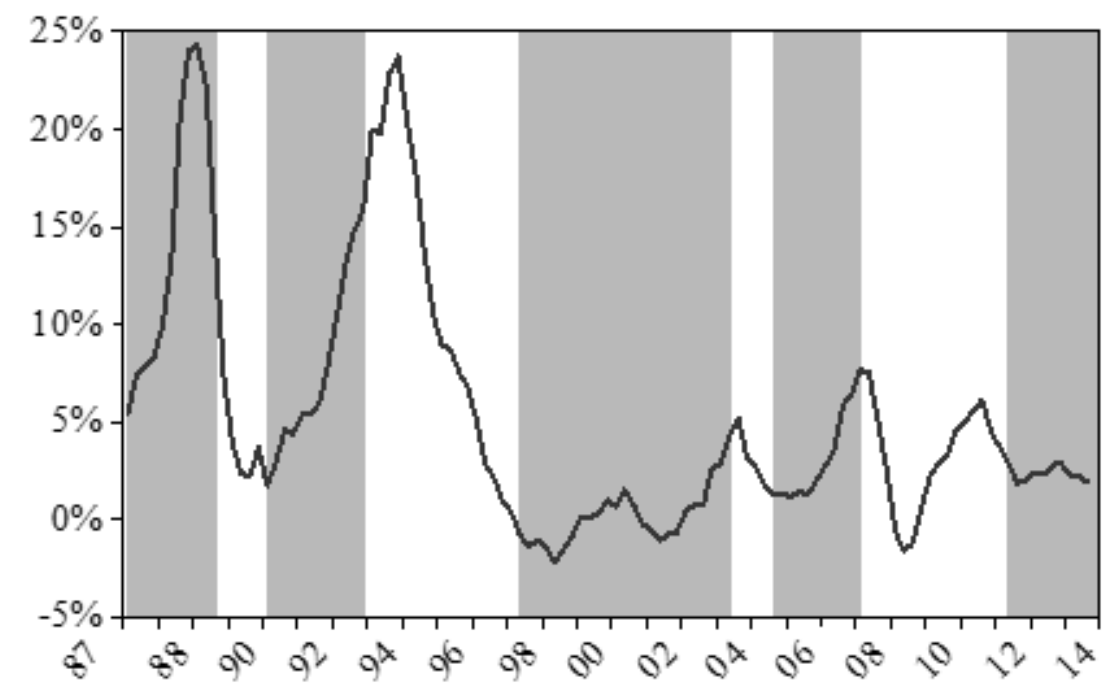

$\square$ State I

State 2 
Figure 4 - Representation of a Concave Phillips Curve

Source: Filardo (1998) \& Author's Research

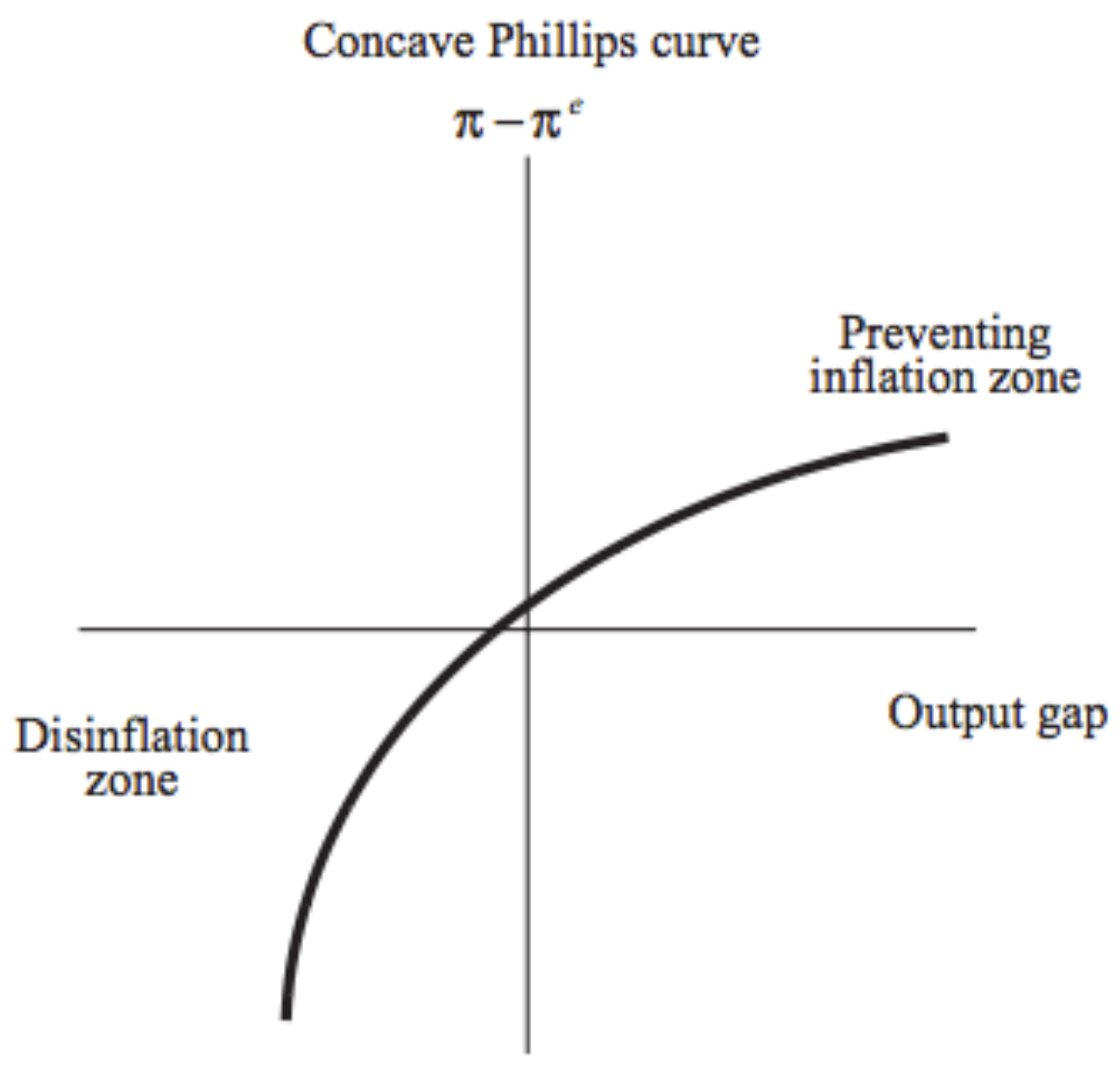

